\title{
Earlier hospital discharge: a challenge for Norwegian municipalities
}

\author{
Heidi Gautun* \\ Centre for Welfare and Labour Research \\ Oslo and Akershus University College of Applied Sciences \\ Email: heidi.gautun@nova.hioa.no \\ *corresponding author
}

\author{
Astri Syse \\ Department of Research \\ Statistics Norway \\ Email: astri.syse@ssb.no
}

\begin{abstract}
Aim: In order to improve patient outcomes and minimize health care costs, many Western countries are attempting to reduce the length of stay in hospitals by transferring responsibilities from specialist care to primary care. In Norway, the Coordination Reform was implemented in 2012 to enhance this development. As a result, the number of patients discharged to the municipal health care services has increased significantly. We investigate the extent to which nurses in nursing homes and home care services feel equipped to provide adequate care for patients discharged from hospitals after the reform.

Data: Altogether, 1,938 nurses representing around $80 \%$ of Norwegian municipalities assessed their experiences of this reform.

Results: An increase in the number of poorly functioning patients discharged to the municipality services was reported. Regardless of place of work, concerns were raised about limited resources in terms of personnel, equipment and competence, as well as an increase in hospital readmission rates. Negative reports on care provision for recently discharged patients came most frequently from nurses in municipalities which generally had low incomes, diverted limited resources to the health care sector and relied heavily on home-based care.

Conclusion: Insufficient transfer of resources to the home care services may have hampered the ability to fulfil the Coordination Reform's intentions of providing safe care to patients in their own homes as an alternative to prolonged hospital stays. Due to a marked increase in reported hospital readmissions, it is not obvious that shorter lengths of stays have reduced overall health care costs.
\end{abstract}

Keywords: Coordination Reform, Hospital, Length of stay, Local care services, Patient flow, Municipal variations 


\section{Introduction}

In order to ensure optimal use of health care resources and improve patient outcomes, many Western countries are aiming to move significant portions of their health care from specialist care to primary care (Deraas, Berntsen, Hasvold, \& Førde, 2011; Holmås, Kamrul Islam, \& Kjerstad, 2013; Purdy et al., 2012). This paper focuses on the overt political aim of reducing the length of stay (LoS) in somatic hospitals, which has been an explicit aim for health authorities in several countries for many years (Clarke \& Rosen, 2001; Kroneman \& Siegers, 2004; Norwegian Ministry of Health and Care Services, 2008-2009). Transferring care-taking responsibilities to local health and care services as soon as possible after somatic hospital treatment is considered to both reduce costs and to be more optimal for patients, as they generally prefer to be cared for in their own homes if such care can be provided safely (Clarke \& Rosen, 2001; Norwegian Ministry of Health and Care Services, 2008-2009). Data from the Organisation for Economic Co-operation and Development (OECD) and European countries show major differences in LoS in hospitals, although it has been reduced over time in most countries (Clarke \& Rosen, 2001; EUROSTAT, 2015). This is also the case for the Norwegian context, which we investigate in this paper.

Since the late 1980s, attempts have been made to reduce the use of specialist care in Norway, in line with explicitly stated political aims, and LoS in hospitals has been gradually reduced (Gautun, Kjerstad, \& Kristiansen, 2001; Norwegian Ministry of Health and Care Services, 2008-2009). In 2009, the average LoS in Norwegian hospitals was less than five days (OECD, 2011). The OECD average was about seven days. There has been considerable growth in the Norwegian municipal health and care services since the late 1980s in terms of both the number of users and the number of employees in these services. The municipality health care costs have increased significantly. The increase in costs has primarily come in home care services (Gautun \& Skrødem, 2015). A reduced LoS in hospitals is only one reason for the observed growth in local health and care sectors. In parallel with the reduced LoS, a number of different reforms have been implemented which altogether have resulted in an increase in both the number of tasks and a change in municipalities' service profiles. As an example, in 1988 the Norwegian Parliament transferred the responsibility for nursing homes from the county level $(N=19)$ to the municipality level $(N=428)$ as part of a general decentralization of primary health care services. This decentralization resulted in the municipalities becoming responsible for the entire primary health and care sector. Concurrent with the transfer of nursing homes, a larger trend towards a general deinstitutionalization with an increased focus on home care services was put in motion (Brevik, 2010). This increase in home care services has, however, only to a limited degree benefitted older age groups (Brevik, 2010). Many of the reforms and initiatives have actually resulted in a pronounced growth in the number of younger users in need of services outside an institution, as exemplified by the 1991 reform concerning individuals with general learning disabilities ("Ansvarsreformen"), the 1998 reform focusing on mental health ("Opptrappingsplanen") and multiple reforms in the field of drug addiction (Gautun \& Syse, 2013).

The process of reducing the LoS in hospitals in Norway has been expedited through the implementation of The Norwegian Coordination Reform in January 2012 (Norwegian Ministry of Health and Care Services, 2008-2009). To reduce the demand for specialized health care services, which was a central aim of the Coordination Reform, more focus has been aimed at preventive services in municipalities. Increased efforts have been directed towards prevention in effort to reduce the number of seriously ill people and to catch problems early, thus 
managing a larger share of health problems at a local level and reducing the LoS at Norwegian hospitals (Norwegian Ministry of Health and Care Services, 2008-2009). Municipal co-financing of many somatic specialized services was introduced in January 2012 as a financial incentive to increase the municipalities' efforts locally (FOR 2011-11-18 nr 1115, §7-15). The municipal co-financing structure was, however, discarded in January 2015, as it did not have the intended effect (Januleviciute, Askildsen, Kaarboe, Siciliani, \& Sutton, 2015). Under the same law, municipalities were legally obliged to bear the costs of hospitalized patients who had finished their treatment from the day such a notice was given. The cost per night was 4,000 Norwegian kroner (NOK) in 2012 and 4,387 NOK in 2015 (National Budget, 2012 and 2015). The number of hospital bed days has fallen significantly after the implementation of the reform (Norwegian Directorate of Health, 2016). Consequently, local care services are expected to handle both a greater total number of patients and more patients with more extensive needs than previously.

An important prerequisite for the explicit aim of the Coordination Reform that patients will receive better health services if they are discharged faster to the local services, is that the municipalities are adequately prepared to provide the warranted services in terms of timeliness and quality. Financial incentives have therefore been put in place to improve staffing in home care services and to upgrade nursing homes in municipalities to provide for patients with extensive medical needs, thus aiming to meet the predicted extra needs in the municipalities as a result of this change in responsibilities (Norwegian Ministry of Health and Care Services, 2008-2009). At the same time, a greater share of the State's resources has been transferred to the municipalities. The question remains as to whether such incentives and transfers have been sufficient, and whether municipalities have responded by allocating adequate resources to their health and care services. In this study, we assess whether employees in local care services believe that they have the warranted resources to provide adequate care to patients discharged from hospitals post-reform. We focus on resources in terms of personnel, competence and equipment.

A literature review presented by the authors in 2013 suggests that most studies have evaluated the reform based either on register data, on interviews with management staff in hospitals and municipalities, or on analyses of the formal collaboration agreement between hospitals and municipalities (Gautun \& Syse, 2013). Official statistics provide information about changes in hospital admissions, LoS and readmissions (Norwegian Directorate of Health 2016) and show reduced LoS, but these data lack information about where the patients are discharged. As such, we do not know the number of patients discharged to home care services and nursing homes. Further, statistics show no changes in the number of readmissions in the period 2011-2015. However, there has been an increase in readmissions for older patients, whereas there has been a decrease for children. This increase may have influenced the local services, because the patient groups in nursing homes are older people and this population is also the largest group receiving home care services. The new Health and Care Services Act from 2012 commits municipalities and health enterprises to sign a cooperation agreement. The agreements aim to promote collaboration between municipalities and health enterprises. Evaluations based on document analysis and interviews with informants at top levels in the administrations conclude that those agreements may constitute a useful framework for coordination between hospitals, but cannot replace the day-today dialogue in discharging patients from hospital to municipal services (Gautun, Martens, \& Veenstra, 2016). Therefore, a survey among nurses working in nursing homes and home care services may give important additional information about whether changes in LoS and readmissions has increased the 
pressure on the local services. A survey may also give important information about whether employees in local care services believe that they have the warranted resources to provide adequate care to patients discharged from hospitals post-reform. This paper analyses data from a survey conducted with 1,938 nurses working in nursing homes or home care services 18 months after the reform was first implemented. As far as we know, this is still the first nationwide study conducted in Norway to investigate employees' experiences of changes resulting from the increased discharge of hospital patients. We aim to assess which services have received the greatest influx of patients from hospitals, how poorly functioning these patients are, and whether the nurses working in local health care services perceive that the services they work in are adequately staffed and have the necessary medical equipment to manage the increased influx. Next, we focus on whether there are differences between nursing homes and home care services in perceived service provision. Lastly, we examine whether there are variations in the experience of nurses based on characteristics of municipalities in terms of size, geographical location, age structure, general economic flexibility and budget constraints, as well as in terms of service profiles (home health versus institutionalized care).

\section{Experiences in nursing homes versus home care services}

It may be hypothesized that the experiences of nurses post-reform will depend on work setting. Efforts have been made since the early 1980 s to deinstitutionalize care services, and HCS have expanded over the last three decades (Gautun \& Grødem, 2015). Prior to the Coordination Reform, nursing homes often represented an end-stage in the care trajectory for patients with too numerous and too advanced needs to be adequately cared for at home. As the Coordination Reform aims to transfer advanced care to local services, the position of nursing homes has been strengthened somewhat - and nursing homes have also been assigned a more temporary function - to accommodate poorly functioning patients unsuitable for home care services shortly after hospital discharge. It may be hypothesized that the different aims and organization of nursing homes and home care services will influence nurses' experiences. Whereas patients generally have more advanced needs in nursing homes, there are usually teams of nurses or other health care personnel available to provide advice. In home care services, nurses typically work independently (Gautun \& Syse, 2013). One of our main aims, therefore, is to compare the situation experienced in these different settings post-reform.

\section{Municipal variation}

Pre-reform register data from Statistics Norway show that the financial situation of the local care setting was more optimal for smaller municipalities than larger municipalities, largely due to inherent characteristics of the previous financial reimbursement systems (Gautun et al., 2001). As such, smaller municipalities may have been better equipped to finance necessary personnel, medical equipment and continuing education than larger municipalities following the reform. On the other hand, it may be the case that the supply of qualified health workers, who have become more in demand since the reform, has been more favourable in larger municipalities. Research also shows that municipality characteristics, such as the population's age structure and the municipality's economic flexibility and service profiles, are associated with the care needs of the inhabitants, as well as the types and extent of services that are made available to them (Langørgen, 2004). As an example, municipalities with a large 
share of older people may also have had great pressure on their services prior to the reform. As such, nurses in these settings may experience a more pronounced lack of resources to deal with the extra burden of additional discharged hospital patients. Furthermore, health and care services are costly. It is reasonable to expect that nurses in municipalities with relatively high incomes may consider themselves to be in a better position to provide services to their patients than nurses working in municipalities with relatively low incomes. The same applies to the general economic flexibility of municipalities. Lastly, the service profiles of municipalities, i.e. the extent to which they divert resources to local healthcare, and whether the provision is largely home-based or institutionalized, may impact the perceived adequacy post-reform. Municipalities with an institutionalized focus may be better equipped to provide care for patients in need of more advanced care. Municipalities with a strong focus on HCS may, on the other hand, be able to handle a larger number of patients. As such, we aim to assess how the characteristics of municipalities impact nurses' perceptions post-reform.

\section{Data and Methods}

\section{Data}

In May 2013, 2,372 nurses working in nursing homes and/or home care responded to a web-based questionnaire administered to a maximum of 10,000 email addresses of members of the Norwegian Nurse Association. Altogether, two reminders were sent. Due to incomplete email registers, an accurate response rate could not be calculated.

Initially, six qualitative interviews were undertaken with nurses in nursing homes and home care services in three different municipalities in Norway. The interviews were performed face-to-face and recorded for later transcription. Based on these qualitative interviews and following general survey design criteria of balanced positive/negative questions and balanced response options, a quantitative web-based questionnaire was designed. Next, the survey questions and response options were piloted on a convenience sample of 12 nurses who had previously worked in either home care services or nursing homes. Minor revisions were then made based on feedback from the pilot participants.

The vast majority (97\%) was employed in the municipality, whereas the remaining was employed in private enterprises or non-governmental organizations. Around one fourth (23\%) stated that they had leadership responsibilities within their services, whereas the remaining majority worked as executive nurses without leadership responsibilities. None of the respondents worked solely in administrative positions. The main aim of the questionnaire was to assess the experiences of municipality healthcare nurses associated with the earlier hospital discharge of patients that resulted from the Coordination Reform. We thus limited our sample to the $82 \%$ employed at the same place before and after the reform $(\mathrm{N}=1,938)$.

In order to identify the characteristics of municipalities that may help to explain differences in perceived effectiveness in handling discharged patients, we linked our survey data to register data from Statistics Norway on such 
characteristics from the 2012 KOSTRA database by means of unique municipality identifiers. More than $80 \%$ of Norway's 428 municipalities were represented in the study by one or more nurse (range=1-151).

\section{Dependent variables}

Changes in the number of patients discharged to nursing homes and home care services were assessed by the question, "Has your service been receiving an increasing or a decreasing number of patients since the reform?" We assessed changes in the number of poorly functioning patients discharged to the services by the question, "Has there been a change in the number of patients that have to be readmitted to hospitals within a week of discharge?" The response categories were: considerably fewer, fewer, no change, more and considerably more. For all measures, we used a simplified categorization in the analyses to facilitate multinomial analyses: no change (no change or missing), an increase (some or considerable increase) and a decrease (some or considerable decrease).

We assessed the resource situation in the services using multiple questions. In terms of personnel, we used the following statements: a) "The service is sufficiently staffed to handle the patients we receive"; b) "The number of staff without formal qualifications is too high"; and c) "There is an adequate number of nurses on staff'. Competence was assessed by the following statements: "I am less confident in the tasks I need to accomplish", and "I need training and guidance to enable me to accomplish the new tasks". In terms of medical equipment, we asked respondents to state their view on the following statement: "Our service has the medical equipment needed to handle the discharged patients". For all the above statements, the response categories were: fully agree, partly agree, indifferent, partly disagree and fully disagree. A simplified categorization was also used here in the analyses: indifferent (including missing), agree (partly or fully) and disagree (partly or fully). In addition, respondents were asked if they had been offered the chance to partake in various competency enhancing and/or educational measures relating to the reform.

\section{Covariates}

Our main interest was the degree to which the experiences of nurses varied across work place, i.e. home care versus services nursing homes, and across municipalities. Categorizations and distributions are shown in Tables 1 and 2. Of the 1,938 nurses, 815 worked only in home care services, whereas 904 worked only in nursing homes. The remaining 219 worked in both settings, and were thus not included in the comparison. Nurses identified the municipality they worked in, thus enabling us to extract information on their municipality, such as size, degree of centralization and geographic location. There are currently 428 municipalities in Norway, varying in size from about 200 inhabitants to more than 600,000 . While $75 \%$ of the municipalities have fewer than 10,000 inhabitants, the proportion of the population who live in small municipalities is only $28 \%$ (Statistics Norway). Four levels of centralization are used by Statistics Norway, based on both municipality size and distance from a large city and ranging from completely decentralized (0) to fully centralized (3). Nurses' sex, age and years of work experience were included in the multivariate models. We only reported covariates which significantly influenced results. 
For a demographic profile on the need for health and care services, we used the share of inhabitants aged 80 and older. For general economic flexibility and budget constraints, we used two indexes: available incomes and unavoidable costs. For service profiles, we examined the net percentage of the total municipality budget used for health and care, and the relative percentage spent on institutionalized care versus home care services. For the latter variable, we created an index of the relative percentage spent on institutionalized care by dividing the relative percentage spent on institutionalized care by that spent on both institutionalized care $(7-87 \%$, mean $45 \%)$ and home care services (12$88 \%$, mean $48 \%$ ). Table 2 provides an overview of the range, median, mean, standard error (SE) and $95 \%$ confidence interval $(\mathrm{Cl})$ of these continuous variables. To ease interpretation, the variables were dichotomized in the regression analyses, but linear parameterizations gave very similar results (not shown). The variable 'share of elderly $80+$ ' could not be included at the same time as 'budget for health and care' due to collinearity. Such collinearity was also observed for the variables 'unavoidable costs' and 'available income', and the latter variable was preferred in multivariate analyses as its effect tended to be more pronounced.

\section{Methods}

To assess changes associated with the reform across work settings (nursing homes versus home care services) and municipalities, we employed descriptive statistics and univariate and multivariate multinomial logistic regression analyses to examine both positive and negative outcomes. The few individuals who gave no response on outcome variables were included in the reference category of 'no change' in the relevant analyses (Table 3 ), while missing responses on covariates were handled by means of imputation. A robustness check excluding individuals with missing information gave virtually identical results. All analyses were undertaken in Stata 13, and the statistical significance level was set at $5 \%$.

\section{Results}

\section{Descriptives}

The vast majority of nurses were female (94\%). Their mean age was 43.4 (range 23-69, S.E. 0.2), and the mean number of working years was 12.4 (range 1-44, S.E. 0.2). Details on the age and work experience of nurses by work place are shown in Table 1.

Around $47 \%$ of respondents were employed only in nursing homes, while $42 \%$ worked only in home care services. A total of $8 \%(\mathrm{~N}=161)$ worked in both places, whereas the remaining $3 \%(N=58)$ worked elsewhere. 
Table 1. Background characteristics (\%) of nurses and their municipalities by work place (home care services vs nursing home).

\begin{tabular}{|c|c|c|c|}
\hline & $\begin{array}{c}\text { All nurses } \\
(\mathrm{N}=1,938)\end{array}$ & $\begin{array}{c}\text { Only HCS } \\
(N=815)\end{array}$ & $\begin{array}{c}\text { Only NH }{ }^{b} \\
(N=904)\end{array}$ \\
\hline Sex & & & \\
\hline $\begin{array}{l}\text { Female } \\
\text { Male }\end{array}$ & $\begin{array}{c}94 \\
6\end{array}$ & $\begin{array}{c}93 \\
7\end{array}$ & $\begin{array}{c}95 \\
5\end{array}$ \\
\hline $\begin{array}{l}\text { Age group } \\
23-29 \text { years } \\
30-39 \text { years } \\
40-49 \text { years } \\
50-59 \text { years } \\
60-69 \text { years } \\
\text { Missing }\end{array}$ & $\begin{array}{l}12 \\
27 \\
28 \\
25 \\
7 \\
1\end{array}$ & $\begin{array}{c}13 \\
28 \\
31 \\
23 \\
5 \\
<1\end{array}$ & $\begin{array}{l}12 \\
27 \\
25 \\
26 \\
9 \\
1\end{array}$ \\
\hline $\begin{array}{l}\text { Work experience } \\
1-4 \text { years } \\
5-9 \text { years } \\
10-14 \text { years } \\
15-19 \text { years } \\
20+\text { years } \\
\text { Missing }\end{array}$ & $\begin{array}{c}20 \\
25 \\
19 \\
13 \\
22 \\
1\end{array}$ & $\begin{array}{l}19 \\
27 \\
19 \\
15 \\
19 \\
1\end{array}$ & $\begin{array}{l}21 \\
25 \\
19 \\
11 \\
23 \\
1\end{array}$ \\
\hline $\begin{array}{l}\text { Inhabitants in work municipality } \\
<3,000 \\
3,001-20,000 \\
20,001-50,000 \\
50,001+\end{array}$ & $\begin{array}{c}7 \\
43 \\
21 \\
29\end{array}$ & $\begin{array}{c}7 \\
40 \\
22 \\
31\end{array}$ & $\begin{array}{l}15 \\
46 \\
19 \\
20\end{array}$ \\
\hline $\begin{array}{l}\text { Degree of centralization } \\
\text { Completely decentralized } \\
\text { Mostly decentralized } \\
\text { Mostly centralized } \\
\text { Completely centralized }\end{array}$ & $\begin{array}{c}12 \\
7 \\
22 \\
58\end{array}$ & $\begin{array}{c}11 \\
5 \\
25 \\
59\end{array}$ & $\begin{array}{c}11 \\
9 \\
19 \\
61\end{array}$ \\
\hline $\begin{array}{l}\text { Health region } \\
\text { Northern Norway } \\
\text { Mid Norway } \\
\text { Western Norway } \\
\text { South-Eastern Norway (excl. Oslo) } \\
\text { Oslo }\end{array}$ & $\begin{array}{l}10 \\
20 \\
18 \\
46 \\
6\end{array}$ & $\begin{array}{c}9 \\
19 \\
14 \\
52 \\
6 \\
\end{array}$ & $\begin{array}{c}9 \\
21 \\
21 \\
42 \\
7\end{array}$ \\
\hline
\end{tabular}

${ }^{a} \mathrm{HCS}$ is short for home care services. ${ }^{\mathrm{b}} \mathrm{NH}$ is short for nursing homes.

The nurses represent centralized and decentralized municipalities of different sizes, and all four health regions in Norway are represented (Table 1). As both the municipalities and the health regions vary in size, this is reflected in the number of responses. 
Table 2. Descriptive statistics on municipality characteristics.

\begin{tabular}{|c|c|c|c|c|c|}
\hline & Range & Median & Mean & S.E. ${ }^{a}$ & $95 \% \mathrm{Cl}^{\mathrm{b}}$ \\
\hline Number of inhabitants & $668-613,285$ & 20995 & 84901 & 3708 & $77,628-92,174$ \\
\hline Degree of centralization & $0-3$ & 1,03 & 2,28 & 0,02 & $2.23-2.32$ \\
\hline $\begin{array}{l}\text { Share of inhabitants age } \\
80+(\%)\end{array}$ & $2.04-8.97$ & 4,48 & 4,56 & 0,03 & $4.51-4.61$ \\
\hline Index of available income & $0.81-1.99$ & 0,91 & 0,93 & 0,002 & $0.93-0.94$ \\
\hline Index of unavoidable costs & $0.76-1.70$ & 0,84 & 0,88 & 0,003 & $0.87-0.88$ \\
\hline $\begin{array}{l}\text { Percent of total budget } \\
\text { diverted to health and care }\end{array}$ & $19.0-54.0$ & 30,85 & 30,45 & 0,11 & $30.23-30.67$ \\
\hline $\begin{array}{l}\text { Degree of health care } \\
\text { institutionalization } 80+(\%)\end{array}$ & $5.59-63.43$ & 36,69 & 35,56 & 0,18 & $32.21-35.91$ \\
\hline
\end{tabular}

${ }^{a}$ S.E. is short for standard error. ${ }^{b} \mathrm{Cl}$ is short for confidence interval.

Table 2 presents further municipality characteristics: the share of inhabitants aged 80 and older ranged from 2-9\%. In terms of economic flexibility and budget constraints, the available income index ranged from 0.81-1.99 and the unavoidable costs index ranged from $0.76-1.70$. The net percentage of the total municipality budget used for health and care varied from $19-54 \%$, whereas the relative percentage spent on institutionalized care varied from $6-63 \%$.

\section{Experiences in home care services versus nursing homes}

Nearly $70 \%$ of respondents stated that there had been an increase in the number of patients discharged to their services after the Coordination Reform (Table 3). The nurses reported a marked increase in the number of patients with cancer and/or in need of palliative care, as well as those with orthopaedic or geriatric needs, or suffering from infection or dementia. The most pronounced difference between reports from nurses in home care services and nursing homes were observed for patients with cancer or general geriatric problems, a population observed to a greater extent in home care services, whereas more patients with dementia were observed in nursing homes.

After the reform, $78 \%$ of home care services nurses reported some or a considerable increase in the number of patients discharged to their services, whereas this was true for only $57 \%$ of nursing home nurses. Similarly, a high proportion of nurses both in home care services $(67 \%)$ and nursing homes $(45 \%)$ reported an increase in the number of poorly functioning patients discharged to their services, as assessed by a question on readmission rates to hospitals within one week. These differences were statistically significant in both univariate and multivariate analyses (Table 4). Very few nurses reported a decrease in the number of poorly functioning patients post-reform, and the difference between nurses in home care services and nursing homes was not statistically significant (not shown). 
Table 3. Descriptive statistics on reported changes (\%) in patient flows following the Coordination Reform, by work place. ${ }^{\text {a }}$

\begin{tabular}{lll}
\hline & $\begin{array}{l}\text { Home care } \\
\text { services (N=815) }\end{array}$ & $\begin{array}{c}\text { Nursing } \\
\text { homes } \\
\text { (N=904) }\end{array}$ \\
\hline $\begin{array}{l}\text { How would you describe the number of patients } \\
\text { compared to before the reform? }\end{array}$ & 20 & 40 \\
No or minor change & 1 & 3 \\
Significantly fewer & 78 & 57 \\
Significantly more & & \\
& & 49 \\
Which diagnostic groups comprise the majority of the increase? & \\
Cancer & 67 & 57 \\
Palliation & 57 & 44 \\
Orthopaedic & 46 & 42 \\
Infections & 46 & 39 \\
Geriatric & 46 & 40 \\
Lung & 39 & 46 \\
Dementia & 36 &
\end{tabular}

How would you describe the number of patients readmitted quickly to hospitals today as compared to before the reform?

$\begin{array}{lll}\text { No or minor change } & 30 & 49 \\ \text { Significantly fewer } & 3 & 6 \\ \text { Significantly more } & 67 & 45\end{array}$

The service is sufficiently staffed to handle the patients we receive

Fully or partly agree

Indifferent

Partly or fully disagree

The number of staff without formal qualifications is too high

Fully or partly agree

Indifferent

Partly or fully disagree

There is an adequate number of nurses on staff

Fully or partly agree

Indifferent

Partly or fully disagree

$\begin{array}{ll}36 & 30 \\ 8 & 9\end{array}$

Our service has the medical equipment needed to handle the discharged patients Fully or partly agree Indifferent

Partly or fully disagree

I am less confident in the tasks I need to accomplish Fully or partly agree Indifferent

Partly or fully disagree 33

I need guidance to enable me to accomplish the new tasks

Fully or partly agree

Indifferent

Partly or fully disagree

aThis Table highlights differences in nurses' perceptions across $\mathrm{NH}$ and HCS and, as such, only nurses working in either place have been included. All responses were provided at one point in time, with questions posted retrospectively. The number of missing responses ranged from $\mathrm{N}=17(<1 \%)$ to $\mathrm{N}=75(<5 \%)$. The missing responses were included in the mid-group, comprising the reference group 'no change' in the multinomial analyses. A robustness check excluding individuals with missing responses gave very similar results, both in terms of percentage distributions and the effect estimates resulting from the multivariate models. 'This list is based solely on those reporting 'significantly more' in the question above $(\mathrm{N}=1,307)$. As individuals could tick all boxes, the percentages do not add up to a hundred. 
Table 4. Multinomial multivariate estimates of the associations between nurses' characteristics and perceived changes following the Coordination Reform $^{\text {a }}$

\begin{tabular}{|c|c|c|c|c|c|c|c|c|c|c|}
\hline & \multicolumn{2}{|c|}{$\begin{array}{l}\text { Influx of patients to } \\
\text { service }\end{array}$} & \multicolumn{2}{|c|}{$\begin{array}{l}\text { Rapid hospital } \\
\text { readmissions }\end{array}$} & \multicolumn{2}{|c|}{ Unqualified staff } & \multicolumn{2}{|c|}{$\begin{array}{c}\text { Medical } \\
\text { equipment }\end{array}$} & \multicolumn{2}{|c|}{$\begin{array}{l}\text { Confidence and } \\
\text { competence }\end{array}$} \\
\hline & \multicolumn{2}{|c|}{ Increased ${ }^{\mathrm{b}}$} & \multicolumn{2}{|c|}{ Increased $^{c}$} & \multicolumn{2}{|c|}{ Too many ${ }^{d}$} & \multicolumn{2}{|c|}{ Adequate $^{e}$} & \multicolumn{2}{|c|}{ Less confident ${ }^{t}$} \\
\hline & $\mathrm{OR}^{9}$ & $p$-value & OR & $\begin{array}{l}\text {-value } \\
\text { p- }\end{array}$ & OR & $p$-value & OR & $p$-value & OR & $p$-value \\
\hline Home care services (ref=nursing home) & 2,69 & $<0.001$ & 2,43 & $<0.001$ & 0,76 & 0,05 & 0,53 & $<0.001$ & 0,79 & 0,05 \\
\hline Male (ref=female) & 1,33 & 0,25 & 0,96 & 0,85 & 0,79 & 0,39 & 0,83 & 0,50 & 0,87 & 0,59 \\
\hline Age $<40($ ref=age $40+)$ & 1,24 & 0,10 & 1,31 & 0,02 & 1,11 & 0,53 & 1,14 & 0,43 & 0,92 & 0,59 \\
\hline Work experience $<10$ yrs $($ ref $=10+\mathrm{yrs})$ & 1,14 & 0,31 & 1,07 & 0,58 & 1,05 & 0,80 & 1,16 & 0,37 & 1,58 & $<0.01$ \\
\hline
\end{tabular}

aMultinomial models of perceived changes post-reform. No significant differences were observed between nurses working in home care services (HCS) versus nursing homes $(\mathrm{NH})$ for a reduced patient load, a reduction in rapid hospital readmissions, a sufficiently qualified staff, an inadequate medical equipment situation or in terms of feeling safe and competent. As such, these estimates are not shown (available on request). ${ }^{\mathrm{b}}$ The univariate OR for HCS nurses relative to $\mathrm{NH}$ nurses was virtually identical: $2.71(95 \% \mathrm{Cl} 2.18-3.37)$. ${ }^{\circ}$ The univariate $\mathrm{OR}$ for $\mathrm{HCS}$ nurses relative to $\mathrm{NH}$ nurses was identical: $2.43(95 \% \mathrm{Cl} 1.99-2.98)$. ${ }^{\mathrm{d}}$ The univariate OR for HCS nurses relative to NH nurses was identical: $0.76(95 \% \mathrm{Cl} 0.58-1.00)$. ${ }^{\mathrm{e}}$ The univariate OR for HCS nurses relative to $\mathrm{NH}$ nurses was virtually identical: $0.52(95 \% \mathrm{Cl} 0.40-0.69)$. ${ }^{\mathrm{f}}$ The univariate OR for HCS nurses relative to $\mathrm{NH}$ nurses was virtually identical: $0.79(95 \% \mathrm{Cl} 0.62-1.01)$. ${ }^{9}$ Odds ratio. ${ }^{\text {h}} 95 \%$ confidence interval.

There appeared to be relatively few differences between nurses in home care services and nursing homes in the assessment of the availability of resources in local services. A higher percentage of nurses in nursing homes $(67 \%)$ than in home care services $(61 \%)$ found the number of unqualified staff to be too high, and the difference was statistically significant in multivariate models (Table 4). However, almost the same number of nurses in home care services and nursing homes disagreed (23\% and $20 \%$, respectively). In terms of the number of nurses on staff, a large proportion of nurses both in home care services and nursing homes ( $56 \%$ and $61 \%$, respectively) stated that they disagreed that this was adequate, whereas approximately $36 \%$ and $30 \%$, respectively, reported that they found it adequate. As such, there were no statistically significant differences between the two groups. Also in terms of overall staffing, there was almost no difference between nurses in home care services and nursing homes: $32 \%$ in home care services and $29 \%$ in nursing homes reported that their service was adequately staffed to handle the patients received, whereas $60 \%$ and $61 \%$, respectively, disagreed.

Younger respondents and respondents with little work experience found the medical equipment situation to be inadequate to a much larger extent than older respondents with longer work experience (not shown). This was true in both settings. However, there were also statistically significant differences between nurses in home care services and nursing homes in this area: whereas only $29 \%$ of nurses in home care services agreed that the medical equipment was adequate, $41 \%$ of nurses in nursing homes agreed that the medical equipment was adequate (Table 4$)$.

In terms of competence, nursing home nurses reported feeling less confident more often than home care services nurses $(39 \%$ versus $33 \%, p=0.03)$, whereas the proportion who reported that they disagree was fairly similar in the two settings ( $37 \%$ and $40 \%$, respectively). Regardless of setting, nurses with less work experience were more likely to report feeling less confident (OR 1.6, $p<0.01)$. In terms of training and guidance, more than $70 \%$ of nurses - 
regardless of setting - stated that they would benefit from such measures. As such, there was no difference between the nurses in this area. Across most questions, only minor and statistically insignificant differences were observed across respondents' characteristics, i.e. sex, age and work experience (Table $4)$.

Respondents were also asked if they had been offered the chance to partake in various competency enhancing and/or educational measures to prepare for the reform. The most common measure that had been implemented (around 30\%) was a telephone 'hot line' to hospitals where specific questions could be directed. In general, less than $20 \%$ had been offered continued education of some sort. However, few respondents had partaken in such measures and the variation in response rates was minor. Thus, no meaningful analyses could be conducted.

\section{Differences between municipalities}

Table 5 presents effect estimates for municipality and nurse characteristics associated with the main outcome variables. Univariate multinomial analyses showed that an increase in patient influx was reported most frequently by nurses in the smallest municipalities, in municipalities with low incomes or high unavoidable costs, or in municipalities which diverted a small percentage of their budget to health and care or had a large share of elderly patients (aged $80+$ ). Nurses in less central areas, however, reported an increase in patient influx less frequently (OR $0.6,0=0.03$ ). In multivariate analyses, only the effects of municipality size, health and care budget and income remained similar. Nurses in home care services below the age of 40 were also more likely to report an increased patient influx. None of the variables were statistically significant in multivariate analyses of a decrease in patient influx, and in univariate analyses only nurses in municipalities with an institutionalized care profile were likely to report this.

Multivariate analyses for an increase in rapid hospital readmissions showed a roughly similar pattern: Nurses in municipalities with low incomes and low health and care budgets were most likely to report an increase. In univariate analyses, the same was true for municipalities with a large share of the elderly. Here also, younger nurses working in home care services were most likely to report an increase. None of the variables reached statistical significance in univariate or multivariate analyses of a decrease in rapid readmissions.

In the assessment of availability of resources in the local services, the only municipal characteristic predicted to have inadequate medical equipment was a low health and care budget. It was, furthermore, most commonly reported by younger nurses with relatively limited work experience. In the analysis of the opposite outcome, i.e. that the medical equipment situation was adequate, univariate analyses showed that this was reported less frequently in larger municipalities and more frequently in municipalities with limited unavoidable costs, however, these results did not hold up in the multivariate analysis. 
Table 5. Multinomial analyses of characteristics of municipalities and nurses associated with perceived changes in the work tasks after the Coordination Reform ${ }^{a}$

\begin{tabular}{|c|c|c|c|c|c|c|c|c|c|c|}
\hline & \multicolumn{2}{|c|}{$\begin{array}{l}\text { Influx of patients } \\
\text { to service }\end{array}$} & \multicolumn{2}{|c|}{$\begin{array}{l}\text { Rapid hospital } \\
\text { readmissions }\end{array}$} & \multicolumn{2}{|c|}{ Unqualified staff } & \multicolumn{2}{|c|}{$\begin{array}{c}\text { Medical } \\
\text { equipment }\end{array}$} & \multicolumn{2}{|c|}{$\begin{array}{l}\text { Confidence and } \\
\text { competence }\end{array}$} \\
\hline & \multicolumn{2}{|c|}{ Increased ${ }^{b}$} & \multicolumn{2}{|c|}{ Increased $^{c}$} & \multicolumn{2}{|c|}{ Too many ${ }^{d}$} & \multicolumn{2}{|c|}{ Inadequate ${ }^{e}$} & \multicolumn{2}{|c|}{ Less confident ${ }^{t}$} \\
\hline & $\mathbf{O R}^{9}$ & $p$-value & OR & p-value & OR & $\mathrm{p}$-value & OR & $p$-value & OR & p-value \\
\hline \multicolumn{11}{|l|}{ \# of inhabitants } \\
\hline$<10,000$ & 1,36 & 0,03 & & & 1 & ref & & & & \\
\hline $10,000-50,000$ & 1,17 & 0,26 & & & 1,47 & 0,02 & & & & \\
\hline $50000+$ & 1 & ref & & & 1,94 & $<0.001$ & & & & \\
\hline \multicolumn{11}{|l|}{ Share of inhabitants age $80+{\text { (cont. })^{\mathrm{h}}}^{\mathrm{h}}$} \\
\hline Low available income (ref=high) & 1,36 & 0,01 & 1,27 & 0,03 & 1,35 & 0,05 & & & 1,26 & 0,05 \\
\hline Low budget for health and care (ref=high) & 1,69 & $<0.01$ & 1,39 & 0,03 & & & 1,66 & 0,02 & 1,43 & 0,04 \\
\hline Work in HCS (ref=NH) & 2,74 & $<0.001$ & 2,44 & $<0.001$ & 0,76 & 0,05 & & & & \\
\hline Age $<40($ ref=age $40+)$ & 1,34 & 0,01 & 1,36 & $<0.01$ & & & 1.42 & 0.02 & & \\
\hline Work experience $<10$ yrs (ref=10+ yrs) & & & & & & & 1.65 & $<0.01$ & 1,61 & $<0.001$ \\
\hline
\end{tabular}

${ }^{a}$ Results from multivariate models of perceived changes in the work situation of nurses post-reform. Originally, all variables from tables 1 and 2 were included in the models for each outcome. Some variables did not make a significant contribution for any of the study's outcomes portrayed here, and are thus not shown. This pertains to the variables centrality, health region, index of unavoidable costs, institutionalized health care profile and being male. A blank indicates that the variable did not contribute significantly in the particular analysis. Multinomial models were set up, but only nonsignificant findings resulted in the multivariate analyses of a decrease in patient influx, a decrease in rapid hospital readmissions, having a qualified staff, an adequate situation with regard to medical equipment and feeling competent and confident. As such, these results are not shown (available on request). Furthermore, as it is difficult to interpret linear variables, a dichotomized version is showed here. The results were very similar with a linear parametrization (available on request). bUnivariate results were largely similar albeit slightly more pronounced for the variables included in the final model (available on request). In addition, nurses in less central municipalities were less likely to report an increase in patient influx (OR $0.6,0=0.03)$, whereas nurses in municipalities with high unavoidable costs $(\mathrm{OR} 1.32, \mathrm{p}=0.006)$ and with a high share of inhabitants $80+(1.36, p=0.005)$ were more likely to report an increase. In analyses of a decrease in patient influx, only nurses in municipalities with an institutionalized care profile were likely to indicate this to be the case (OR 2.54, $\mathrm{p}=0.006)$. 'Univariate results were largely similar for the variables included in the final model (available on request). In addition, nurses in municipalities with a high share of inhabitants $80+(1.33, p=0.006)$ were more likely to report an increase in rapid hospital readmissions. None of the variables reached statistical significance in univariate analyses of a decrease in rapid hospital readmissions. ${ }^{\text {Un }}$ Univariate results were largely similar albeit slightly less pronounced for the variables included in the final model (available on request). Nurses in municipalities with limited unavoidable costs $(O R 0.67, p=0.002)$ and with a high share of inhabitants $80+(0.75, p=0.03)$ were less likely to report that they had too many unqualified workers on staff, the latter somewhat surprising. In univariate analyses of having an adequately qualified staff, this was more likely to be reported by nurses in high-income municipalities (OR 1.42, $p=0.02$ ). ${ }^{\text {eT }}$ The univariate results were largely similar to those reported on in the multivariate analysis. In analysis of the opposite outcome, i.e. that the medical equipment situation was adequate, univariate analyses showed that this was less frequently reported in larger municipalities (OR $0.70, p=0.02$ and $\mathrm{OR} 0.63, p=0.006$ for the two largest categories, respectively) and more frequently in municipalities with limited unavoidable costs $(\mathrm{OR} 1.45, p=0.005)$. ${ }^{\mathrm{f}}$ The univariate results were somewhat weaker than those portrayed in the multivariate analysis. None of the other variables reached statistical significance in univariate analyses. For reports of not feeling less competent or confident, the only significant results were found for nurses working in municipalities with an institutionalized care profile, and these nurses were less likely to report feeling confident (OR 0.73 , $\mathrm{p}=0.005$ ). ${ }^{9}$ Odds ratio. ${ }^{\text {h}}$ The variable 'share of elderly $80+$ ' could not be included simultaneously with the percentage of the municipality's 'budget for health and care' due to collinearity. In the analyses of rapid readmissions, the effect size of the other covariates was almost identical when the latter variable was swapped with the former (OR 1.35, $p=0.009)$. Such collinearity was also observed for the variables 'unavoidable costs' and 'available income', and the latter variable was preferred in multivariate analyses as its effect tended to be more pronounced.

Looking at reports on adequately qualified staff, this was more likely to be reported by nurses in high-income municipalities. In terms of having unqualified staff, nurses in municipalities with low incomes were more likely to report this, as were nurses employed in larger municipalities. Furthermore, it was most 
commonly reported by nurses working in home care services. In univariate analyses, nurses in municipalities with limited unavoidable costs and with a large share of elderly patients were, somewhat surprisingly, less likely to report that they had too many unqualified workers on staff. In terms of the number of nurses on staff, minor or no differences were observed across nurses in municipalities with different characteristics. In terms of overall staffing, the nurses working in the richest municipalities were most likely to agree that the overall staffing was adequate.

In terms of competence, low levels of confidence were observed most often in low-income municipalities which diverted the least resources towards health and care, whereas the opposite was observed in municipalities relying heavily on institutionalized care. Along the same lines, nurses working in municipalities relying on institutionalized care expressed the least need for guidance (not shown).

\section{Discussion}

The vast majority of nurses in primary health and care services in Norwegian municipalities report that they have received an increasing number of seriously ill patients from hospitals since the implementation of the Coordination Reform. The influx of additional patients is reported most frequently among nurses in home care services who report an upsurge in rapid hospital readmissions and who also appear to receive particularly poorly functioning patients. Such reports may suggest that the home care services sector has been granted insufficient resources to fulfil the obligations explicitly stated in the Coordination Reform, i.e. to safely provide care for patients in their own homes as an alternative to the provision of such care in hospitals.

A survey conducted prior to the Coordination Reform shows that variation in LoS between hospitals may be explained mainly by the capacity of primary health care providers (Kjekshus, 2005). Our findings may suggest that although the primary health care capacity has increased to meet the increased task load, it has not been sufficient to meet the actual demand. As such, the relative capacity may actually have diminished since the reform. Primary health care services, regardless of their resource situation, are mandated to handle discharged hospital patients. As such, the municipalities must ensure that their services can accommodate the need. Services with limited resources appear, however, to rapidly return to hospitals patients they feel inadequately equipped to handle. Nurses in municipalities with a large number of residents with care needs, i.e. a large share of older individuals, and with limited economic flexibility report more frequently that there has been an increase in the number of readmissions. Whereas nurses in the smallest municipalities report the largest influx of patients post-reform, they are the least likely to report staffing problems. This is in line with recent findings, which show that the staff shortage escalates with increasing municipality size (Gautun et al., 2016).

A majority of nurses report that the resources warranted to take on the new and additional tasks are currently largely lacking in terms of both personnel and equipment. More specifically, nurses indicate a need for a larger number of qualified personnel. Medical equipment is particularly needed in home care services. Regardless of work place, measures to raise competence levels are found lacking, as new tasks have been added while the ordinary tasks have become more numerous than previously. This is underscored by our finding that 
only a minority of nurses report that they have been offered competence enhancing measures post-reform, and that the measure most commonly reported is a basic telephone 'hot line' to hospitals for specific questions. Nurses in low-income municipalities indicate that the number of unqualified staff is too high and those working in municipalities diverting the least resources towards health and care felt less competent and confident, whereas the opposite was observed in richer municipalities and in municipalities with a service profile heavily reliant on institutionalized care. Along the same lines, nurses working in municipalities relying on institutional care expressed the least need for guidance.

In general, however, nurses in municipalities where a considerable portion of the budget is allocated to the health and care sector appear to be less negatively affected by the reform. Similarly, municipalities with fewer budget constraints and municipalities relying more heavily on institutionalized care appear to be better off than those with more severe budget constraints and care profiles more reliant on home care services. Our findings on municipal variation align well with those observed across work places, and thus solidify the conclusion that the Norwegian Coordination Reform has had a significant effect on home care services, and not in just a positive manner. In terms of future priorities, resources appear to be urgently needed to further strengthen home care services for the reform to be deemed successful.

It may be that insufficient resources have been directed to the municipalities overall. However, municipalities may also have failed to prioritize home care services to the extent necessary to ensure adequate care to discharged patients. This study has focused on discharged patients' follow-up care in the municipalities, which is one of the challenges resulting from the Coordination Reform. However, investigations of prevention and early intervention efforts in the municipalities are also warranted.

To conclude, insufficient transfer of resources to home care services may have hampered the ability to fulfil the Coordination Reform's intentions of providing safe care to patients in their own homes as an alternative to prolonged hospital stays. Due to a marked increase in reported hospital readmissions, it is not obvious that shorter LoS has reduced overall health care costs. Registry data suggest, however, that the number of hospital readmissions has been stable in the period 2011-2015 (Melberg and Hagen, 2016). This is a result of a combined readmission increase of the elderly and a corresponding decrease of children (Norwegian Directorate of Health, 2016). The services investigated here primarily concern the elderly and, as such, our results are in line with the readmission upsurge for this age group. Our cross-sectional results from around 18 months post-reform also need to be assessed from a patient perspective, and longitudinal follow-up studies are warranted in the continued monitoring of the Coordination Reform to assess whether things have changed for the better at a later stage. Some negative short-term issues are to be expected from any reform implementation, and if such issues are quickly resolved, the final results may nevertheless be positive. This will be interesting to follow in the years to come. 


\section{References}

Brevik, I. (2010). De nye hjemmetjenestene- Langt mer enn bare eldreomsorg. Utvikling og status i yngres bruk av hjemmebaserte tjenester 1989-2007. NIBRrapport 2010:2. Oslo. Norsk Institutt for by- og regionsforskning. https://doi.org/10.7577/nibr/rapport/2010/2

Clarke, A., \& Rosen, R. (2001). Length of stay: How short should hospital care be? The European Journal of Public Health, 11(2), 166-170. https://doi.org/10.1093/eurpub/11.2.166

Deraas, T. S., Berntsen, G. R., Hasvold, T., \& Førde, O. H. (2011). Does long-term care use within primary health care reduce hospital use among older people in Norway? A national five-year population-based observational study. BMC health services research, 11(1), 1. https://doi.org/10.1186/1472-6963-11-287

EUROSTAT. (2015). Hospital discharge and length of stay statistics. Retrieved from http://ec.europa.eu/eurostat/statisticsexplained/index.php/Hospital discharges and length of stay statistics\#Main statistical findings.

Gautun, H., Kjerstad, E. \& Kristiansen, F. (2001). Mellom to senger? Eldre sykehuspasienter og det kommunale pleie- og omsorgstilbudet. SNF-rapport $57 / 01$.

Gautun, H. \& Syse, A. (2013). Samhandlingsreformen. Hvordan tar de kommunale helse- og omsorgstjenestene i mot det økte antallet pasienter som skrives ut fra sykehusene? NOVA Rapport 8/13. https://doi.org/10.7577/nova/rapporter/2013/8

Gautun, H. \& Grødem, A. S. (2015). Prioritising care services: Do the oldest users lose out? International Journal of Social Welfare, 24(1), 73-80. https://doi.org/10.1111/ijsw.12116

Gautun, H., Martens, C. T. \& Veenstra, M. (2016). Samarbeidsavtaler og samarbeid om utskriving av pasienter. Tidsskrift for omsorgsforskning, 2(2), 88-93. https://doi.org/10.18261/issn.2387-5984-2016-02-03

Holmås, T. H., Kamrul Islam, M., \& Kjerstad, E. (2013). Between two beds: inappropriately delayed discharges from hospitals. International Journal of Health Care Finance and Economics, 13(3), 201-217. https://doi.org/10.1007/s10754-013-9135-4

Januleviciute, J., Askildsen, J.E., Kaarboe, O., Siciliani, L., Sutton, M. (2015). How do hospitals respond to price changes? Evidence from Norway. Health Econ, 25(5), 620-636. https://doi.org/10.1002/hec.3179

Kjekshus, L. E. (2005). Primary health care and hospital interactions: effects for hospital length of stay. Scandinavian journal of public health, 33(2), 114-122. https://doi.org/10.1080/14034940410019163

Kroneman, M., \& Siegers, J. J. (2004). The effect of hospital bed reduction on the use of beds: a comparative study of 10 European countries. Social science \& medicine, 59(8), 1731-1740. https://doi.org/10.1016/j.socscimed.2004.01.03

Langørgen, A. (2004). Needs, economic constraints, and the distribution of public home-care. Applied Economics, 36(5), 485-496. https://doi.org/10.1080/00036840410001682197 
Melberg, H.A., \& Hagen, T. (2016). Liggetider og reinnleggelser i somatiske sykehus før og etter Samhandlingsreformen. Tidsskrift for omsorgsforskning, 02(2), 143158. https://doi.org/10.18261/issn.2387-5984-2016-02-09

National Budget. (2012). Innst. 2 S (2011-2012).

National Budget. (2015). Innst. 2 S (2014-2015).

Norwegian Directorate of Health. (2016). Samdataspesialisthelsetjenesten 2015.

Retrieved from:

https://helsedirektoratet.no/Lists/Publikasjoner/Attachments/1219/Samdata\%20 Spesialisthelsetjenesten\%202015\%20IS-2485.pdf

Norwegian Ministry of Health and Care Services. (2008-2009). The Coordination Reform. (47).

OECD. (2011). Health at a glance: OECD indicators. Retrieved from http://www.oecdilibrary.org/sites/health glance-2011en/04/05/index.html;jsessionid=347cdtfdmp3bf.x-oecd-live03?itemld=/content/chapter/health glance-2011-33-

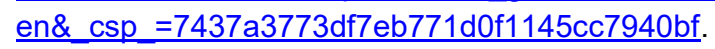
https://doi.org/10.1787/health_glance-2011-en

Purdy, S., Paranjothy, S., Huntley, A., Thomas, R., Mann, M., Huws, D., \& Elwyn, G. (2012). Interventions to reduce unplanned hospital admission. Bristol: National Institute for Health Research. 